\title{
A Different Model in Graduate Education For Full-Time Professionals
}

\author{
Dennis R. Depew, Duane D. Dunlap and Kathryne Newton \\ Purdue University
}

The School of Technology at Purdue University in 1998 began delivering a Weekend Master's Degree Program in Technology aimed at serving working professionals who live all over the Midwest. This program is designed to meet the growing demand for advanced education in technology by taking advantage of the readily accessible technology that now makes distance education possible. The program is a unique interdisciplinary curriculum designed for professionals in a wide variety of industrial and business environments. The curriculum combines courses from manufacturing technology, information technology, and industrial distribution, and requires the completion of a "directed project" that is much like a master's thesis, except that students are expected to tackle an applied problem from their own work environment.

The Weekend Master's Program does not rely solely on distance media for the delivery of instruction, but rather depends on a combination of approximately 55\% face-to-face instruction and $45 \%$ distance delivered instruction. To have real-time intellectual graduate education discussion, stimulation, and physical resource sharing, our graduate education instruction received at a distance is best complemented and supported with face-to-face interaction with peers and faculty during three "weekend" sessions on campus. Students are able to optimize their time by the use of technology to learn the bulk of the course content, but are then able to build their expertise in higher-level experiences provided by social interaction and feedback during case studies, project presentations, and other in-class exercises.

\section{Graduate Education in Technology}

Technology and engineering technology programs continue to change and evolve in striving to meet society's technological expectations and needs. It is imperative that graduate education be considered as an important element. A survey study conducted at Purdue University reported that $92 \%$ of the alumni and faculty indicated that graduate education in technology is important for the professional development of individuals working in industry and that there exists a perceived demand for graduate education in technology and engineering technology ${ }^{1}$. Although this study surveyed only faculty and alumni of Purdue University, and generalizing these findings to a broader level would be inappropriate from a true research point of view, the fact remains that graduate education for technologists is an important issue that must be addressed.

As more individuals graduating from technology-related programs enter the work force, the need for graduate education appropriate for their future professional development will become an important priority in remaining competitive in the international marketplace. In addition to providing advanced studies for individuals in industry, furnishing graduate education for the future professors of technology at the two-and four-year college levels will also become critical in delivering highquality education for future generations of technologists. 
When one merely considers the number of individuals graduating from technology and engineering technology programs today, the need for graduate programs appropriate for these individuals becomes more evident. At Purdue University, the School of Technology graduates approximately 800 individuals each year with baccalaureate degrees from technology and engineering technology programs. The School currently has over 15,000 alumni in the work force, with 8,000 alumni graduating in the past 10 years (School of Technology, 1996). According to the Engineering Workforce Commission Report, in the fall of 1995, 289 schools with four-year degree programs in engineering technology reported 17,394 students were in their third year or later of an engineering technology or technology-related program. Suffice it to say that a significant number of technology and engineering technology graduates will be entering the work force each year (Engineers, 1996).

\section{The Future of Graduate Education for Technology Alumni}

Some graduates from technology and engineering technology programs will choose to pursue graduate study from a business school, perhaps a Master's in Business Administration. The MBA will be an appropriate choice for some; however, some individuals may be searching for advanced study opportunities in an applied area of technology that may only be available from, or appropriately offered by, technology and engineering technology programs within the School of Technology. Moreover, others may wish to find a graduate program that offers sufficient flexibility for interdisciplinary experiences in both technical and business fields of study.

Distance learning is receiving substantial attention today, the issue of flexibility, in terms of delivery, will become increasingly important. Individuals graduating from technology programs will be searching for advanced study opportunities that can be successfully completed without interrupting their career path with their employer or lowering their standard of living by exiting the work force to complete a degree.

Advances in electronic communications have improved the opportunity and quality of televised courses; the ability to conduct teleconferences with two-way audio and video; the use of the computer to conduct library research. The immense power of Internet browsers coupled to the world-wide-web allows one to find information in minutes that once would take days. Technology and engineering faculty now have the ability to deliver high quality and very flexible graduate education opportunities for our discipline.

The future number of technology and engineering technology graduates continuing to enter the work force will have the need for flexible high-quality graduate education programs administered by the School of Technology. These future programs should address the educational needs and requirements of the individual, as well as the employer, who potentially may be providing the necessary financial support. Just as technology and engineering technology programs are evolving and changing to meet the future needs of business and industry at the baccalaureate level, faculty and administrators are well advised to support the future needs of our post-graduates.

\section{The Master of Science Degree}

Realizing that each student has different career goals, academic background, and professional responsibilities, the Master of Science program offers maximum flexibility in developing an individualized plan of study to prepare the individual for attaining these career goals. It is important to note that the Master of Science (M.S.) Degree in Technology for Full-time Professionals consists 
of the same basic course composition as the existing on-campus M.S. in Technology. Only the method of instructional delivery is different. The noted one exception is that students enrolled in the new program will not register for a directed project. Instead, students will complete a three credit hour independent study requirement as the replacement. The proposed program requires a minimum of 30 credit hours of course work. Of the 30 credit hours, each student must complete a 24-credithour core requirement. The remaining six hours will be independent study.

\section{Admission Requirements}

Applicants for admission to the Master of Science program are expected to have completed a baccalaureate degree with a minimum grade point average of at least 3.00 on a 4.00 scale, and must submit acceptable scores on the General Test Section of the Graduate Record Examination. Companies that have employees enrolled in the program include Caterpillar, Subaru-Isuzu of America, Fairfield, Cummins Engine, Johnston \& Johnston, American Electric Power, Tower Automotive, Transilwrap, Inc., TRW, Bosch Brake Systems, Rapid Modeling Corporation, Delco Electronics, Zeneca Resins, U.S. Customs Agency, Delco Remy and Batesville.

Flexible Delivery System

The School of Technology recognizes the need for making graduate education available to the nontraditional student working full-time in business and industry. The faculty and administration of the School believe the greatest potential for future growth in graduate education will be with the nontraditional student. The individual working in business or industry, both in-state and out-ofstate, will require a delivery system which provides maximum flexibility. As a result of job and family responsibilities, these potential student customers will need a non-traditional, high-quality education experience that enhances their professional development with maximum flexibility.

The School of Technology proposes a flexible delivery system for graduate education that provides individuals the opportunity to complete the Master of Science degree in technology in four semesters plus one summer session. The program requires students to come to the West Lafayette Campus for three extended weekends each semester. These extended weekends begin on Friday afternoon and conclude on Sunday afternoon. Students take 1-7 credit hours of course work per semester. Purdue faculty teach the courses, although instructional methodology differs from that of the traditional course structure because course content is delivered by technology in addition to traditional classroom lectures. While students are on campus for instruction with faculty, they learn about the prescribed course content through lecture, supplemented by computer laboratory, library, video, and group case study interaction. By breaking up instruction through different teaching methodologies and physical location throughout the West Lafayette campus, students better learn and retain course content while having an intense instructional period during a given weekend. For any given course taught in this format, students have appropriately 32 hours of contact time with their instructor while on campus. Students continue their studies in their home area and are in contact with the West Lafayette faculty on a weekly basis using distance education technology. Distance education media include the completion of case studies, independent studies, and home work which are submitted electronically to faculty, in addition to CD-ROM self-study programs which complement the goals of the plan of study. The plan of study for the first group admitted to this program of study follows.

\section{MODEL PLAN OF STUDY}


Flexible Masters Degree Program Course Title and Delivery Schedule (weekend program) TECH 564 Measurement and Evaluation in Industry and Technology 3 credits TECH 560 A Microcomputer Applications in Industry and Technology TECH 590 Research and Writing for Business and Industry

3 credits

1 credits

TECH 646 Analysis of Research in Industry and Technology

TECH 621A Automatic Data Collection Technologies for Mfg. and Distribution

3 credits

TECH 590 Problems in Business and Industry

3 credits

1 credit

TECH 623 Contemporary Industrial Technology Problems

3 credits

TECH 590 World Class Manufacturing Strategies

1 credit

TECH 598 Directed M.S. Project Proposal

1 credit

TECH 621B Strategic Planning and Marketing in Industry

3 credits

TECH 571 Project Management and Scheduling in Technology

3 credits

TECH 598 Directed M.S. Project

1 credit

TECH 580 Quality and Productivity in Industry and Technology 3 credits

TECH 621C Distribution Initiatives for the 21st Century

3 credits

TECH 598 Directed M.S. Project

1 credit

30 Total Credit Hours

This program has been successful, and the first cohort group will graduate in May of 2000. Many important lessons have been learned during the implementation of this program.

- Teaching "at a distance" in a weekend format requires different teaching strategies than the traditional classroom.

- The level of importance placed on due dates for assignments should be less than for traditional, on-campus graduate students due to the many demands that these students are juggling.

- Student profiles are an important consideration in designing courses, as well as designing policies for the program's administration.

- Availability of material for students requires advance planning.

- Technology usage must be carefully planned in advance.

- Special attention must be given to the selection of faculty.

- Faculty development is needed for preparation to use different teaching media.

1. Brauer, William M., 1993, Unpublished Doctoral Dissertation, School of Technology, Purdue University.

2. Engineers, 1996, Bulletin on Careers in the Profession Report, Vol. 3, No. 1.

3. Alumni Data, School of Technology, Purdue University, West Lafayette, IN, 1996.

\section{DENNIS R. DEPEW}

Dennis R. Depew is Professor and Dean for the College of Applied Sciences at Western Carolina University. His teaching and scholarly interests are in the area of quality and productivity. He received his Ph.D. from Purdue 
University, and his Bachelor's and Master's Degrees from East Tennessee State University. Dr. Depew holds his rank and tenure in the Department of Industrial and Engineering Technology at Western Carolina University

\section{DUANE D. DUNLAP}

Duane D. Dunlap is an Associate Professor of Industrial Technology at Purdue University and Director of the Weekend Master's Degree Program. His teaching and scholarly interests are in the areas of graduate education and automatic identification and data capture (AIDC). He received his doctorate from Virginia Tech, his Master's from Louisiana State University, and Bachelor's of Science from The Ohio State University and has served on the faculty at Purdue since 1990. Dr. Dunlap conducts applied research and consulting services to a wide variety of manufacturing and distribution companies.

\section{KATHRYNE A. NEWTON}

Kathryne A. Newton is an Associate Professor of Industrial Technology at Purdue University. Her teaching and scholarly interests are in the areas of industrial distribution, total quality management and adult education. She received her Ph.D. and MBA degrees from Texas A\&M University and has served on the faculty at Purdue since 1993. Dr. Newton conducts research and facilitation services to a wide variety of distribution trade associations. 